\title{
A incalibrável competência socioemocional
}

\author{
Guilherme Augusto Rezende Lemos \\ Universidade do Estado do Rio de Janeiro - Brasil \\ Elizabeth Fernandes de Macedo \\ Universidade do Estado do Rio de Janeiro - Brasil
}

\section{Resumo}

Neste texto, os autores discutem a noção de competência socioemocional à luz da ideia, construída com Derrida, de que a educação é uma resposta ao chamado da alteridade. Partindo d BNCC e de documentos políticos exarados por organismos multilaterais - como OCDE e ONU/Banco Mundial -, os autores argumentam que está em curso uma atualização de uma retórica que submete a educação à linguagem econômica e a modelos sistêmicos. Trazendo o exemplo de projeto em desenvolvimento junto a professores de redes de ensino em quatro cidades brasileiras, os autores defendem a necessidade e a urgência de políticas públicas situadas, centradas na experiência escolar e nas interrelações que aí ocorrem.

Palavras-chave: Currículo. Políticas públicas. Neoliberalismo. Competência socioemocional.

\section{The incalibrable socio-emotional competence}

\begin{abstract}
In this text, the authors discuss the notion of socio-emotional competence in light of the idea, constructed with Derrida, that education is a response to the call of otherness. Starting with the BNCC and political documents drawn up by multilateral bodies - such as the OECD and the UN / World Bank - the authors argue that a rhetoric is underway that subjects education to economic language and systemic models. Highlighting the example of a project under development with in-service teachers in four Brazilian cities, the authors defend the need for and urgency of situated public policies centered on the school experience as well as on the interrelationalities that occur there.
\end{abstract}

Keywords: Curriculum. Curriculum policies. Neoliberalismo. Socio-emotional 


\section{La incalibrada competencia socioemocional}

\section{Resumen}

En este texto, los autores discuten la noción de competencia socioemocional a la luz de la idea, construida con Derrida, de que la educación es una respuesta a la llamada de la otredad. Comenzando con el BNCC y los documentos políticos elaborados por organismos multilaterales, como la OCDE y el Banco Mundial / ONU, los autores argumentan que hay una retórica en curso que somete la educación al lenguaje económico y los modelos sistémicos. Destacando el ejemplo de un proyecto en desarrollo con maestros en servicio en cuatro ciudades brasileñas, los autores defienden la necesidad y la urgencia de políticas públicas situadas centradas en la experiencia escolar, así como en las interrelaciones que ocurren allí.

Palabras clave: Currículo. Políticas curriculares. Neoliberalismo. Competencias socioemocionales.

\section{La compétence socio-émotionnelle incalibrable}

\section{Résumé}

Dans ce texte, les auteurs discutent de la notion de compétence socio-émotionnelle à la lumière de l'idée, construite avec Derrida, que l'éducation est une réponse à l'appel de l'altérité. En commençant par la BNCC et les documents politiques élaborés par des organismes multilatéraux - tels que l'OCDE et la Banque mondiale / ONU -, les auteurs affirment qu'une rhétorique est en cours pour soumettre l'éducation à des modèles linguistiques et systémiques. Soulignant l'exemple d'un projet en cours de développement avec des enseignants en poste dans quatre villes brésiliennes, les auteurs défendent la nécessité et l'urgence de politiques publiques localisées centrées sur l'expérience scolaire ainsi que sur les interrelations qui s'y produisent.

Mots-clés: Curriculum. Politiques curriculaires. Néolibéralisme. Compétences socio-affectives. 


\section{Introdução}

Na versão aprovada da Base Nacional Comum Curricular - BNCC (Brasil, 2017), uma das novidades em relação às propostas iniciais foi o foco mais explícito na organização do currículo por competências definidas como:

a mobilização de conhecimentos (conceitos e procedimentos), habilidades (práticas, cognitivas e socioemocionais), atitudes e valores para resolver demandas complexas da vida cotidiana, do pleno exercício da cidadania e do mundo do trabalho. (p.8)

Apesar de trazer as competências, de volta, para o centro do currículo, a BNCC não explicita claramente uma teorização pedagógica específica quando opta por tal organização curricular. Genericamente, defende que um currículo por competência favorece a integração e a contextualização do conhecimento, assim como a centralidade no aluno. Ao mesmo tempo em que assume uma abordagem instrumental - na qual competências e habilidades se equivalem -, a BNCC aponta para competências mais gerais, não claramente vinculadas a um conteúdo específico. Dentre estas, destacam-se as competências denominadas socioemocionais, descritas por Rodrigues (2015) como "comportamentos, atitudes e características de personalidade que não estariam diretamente ligadas ao domínio das disciplinas escolares" (p. 4). Mesmo ainda pouco presentes na BNCC do ensino fundamental, tais competências têm dominado a cena nos materiais de divulgação, visando aos professores, na etapa atual de implementação da Base.

A própria menção ao termo competência, no contexto das políticas curriculares, aponta para um conjunto de referências a organismos multilaterais, ademais referidas na própria BNCC. As mais imediatas são, provavelmente a OCDE, que popularizou o termo ao utilizá-lo no PISA (Programa Internacional de Avaliação de Estudantes); a UNESCO e a ONU - com seu conhecido braço, o Banco Mundial. Se a OCDE tem um enfoque mais economicista e a UNESCO está mais ligada à educação e à cultura, tal diferença não altera substantivamente os vínculos propostos entre escola e mercado. O documento mais icônico, elaborado pela UNESCO em 1993, o Relatório Delors, por exemplo, era explícito ao falar de competências básicas para a participação social, mas também profissional. O que parece estar mudando, mais recentemente, é que, com a crise de empregabilidade, a linguagem das competências não mais promete inserção na cadeia produtiva. Ela passa a se referir, segundo Anderson-Levitt (2017), a competências que garantam maior ligação entre a formação escolar e a vida, passa a prometer uma cidadania global.

Não precisamos de muito esforço para defender que a "racionalidade política contemporânea que posiciona a educação escolar como objeto de intervenção governamental, equacionada enquanto um investimento econômico" (Heckman, entrevista a Carvalho e Dias, 2017, p.175) não tem dado os resultados esperados. As próprias políticas públicas produzidas nesses termos têm fornecido inúmeras evidências da sua incapacidade de lidar com a educação: ano após ano, os resultados 
do PISA não se alteram; cada nova reforma se constrói sobre uma avaliação extremamente negativa da reforma anterior.

Ao longo do texto, pretendemos sustentar que o uso do termo competência como organizador da BNCC - independente do deslocamento do campo estrito da economia e da empregabilidade para o da cidadania global - aprisiona a educação a um modelo sistêmico que a descaracteriza. Assumimos, com Derrida (1989), que a educação é uma resposta ao chamado da alteridade, ela é devida ao outro totalmente outro, aquele que "ainda não foi inventado", que se inventará na relação intersubjetiva. Nessa perspectiva, a ideia de competência - e, mais ainda, de competência socioemocional - como algo que pode ser definido a priori e testado, nos parece impensável.

Apenas como forma de ampliar nosso argumento, ao final deste texto, traremos uma experiência de pesquisa que vimos desenvolvendo junto a professores de quatro diferentes municípios - Niterói (RJ), Rondonópolis (MT), Cachoeira e São Félix (BA). A intervenção que estamos produzindo, com financiamento do CNPq, centrada na ação de cada docente nas escolas em que atuam, é proposta como forma de fazer política pública em currículo. Rejeitando a noção de público como massa amorfa sobre a qual a política deve atuar - tornando os sujeitos competentes, em sentidos previamente definidos -, temos assumido uma ideia de público comprometida com a contingência, a multiplicidade, o local, enfim, a vida das pessoas envolvidas na experiência educacional.

\section{Um certo estado da arte}

Neste texto, partimos da crença de que o debate acerca de competências socioemocionais encontra-se na encruzilhada de muitos outros debates no contexto das relações entre educação e economia. Talvez devêssemos começar por aí, não no sentido de uma retrospectiva histórica que remonta ao século XIX, mas da busca por um "fio da meada" que nos possibilite compreender o ambiente em que essa proposta emerge como saída para a calibragem dos comportamentos, tanto dos professores como dos alunos, para atingirem maiores níveis nas avaliações institucionais.

Lins (2013) alerta que a relação entre economia e educação, em sentido mais amplo, tanto no sentido teórico como na orientação política, não alcançou os efeitos previstos:

No plano da teoria econômica é inegável a contribuição da teoria do capital humano formulada por Theodore Schultz (1961) e Gary Backer ([1964]; 1993). Nela observou-se que o aumento do dinamismo econômico se devia a algo além do mero investimento em capital físico, sendo de extrema importância tanto o investimento em educação quanto o investimento individual na busca por qualificação profissional. (Lins, 2013, p. 1)

Teorias dessa natureza desembocam, com frequência, na ideia da busca individual por qualificação profissional como diferencial para obtenção de maior sucesso 
no mundo do trabalho. Quanto maior a qualificação, maiores as chances de boas colocações no mercado. Este é o argumento que tem subsidiado as orientações/ intervenções de organismos internacionais nas políticas públicas em educação. Parece, entretanto, que os efeitos das orientações dadas por tais organismos para países subdesenvolvidos e em desenvolvimento (nosso caso) não se realizam na prática, pelo menos é o que estudos sobre o PISA têm nos mostrado.

Nesses quase vinte anos de convivência com o Pisa, em que houve tentativas de imposição de certo domínio de perspectivas econômicas ao debate educacional, assistimos a muitos países gastarem milhões de dólares com a realização dessa avaliação. Contudo, de modo geral, as evidências de melhorias nos resultados são modestas e, em alguns casos, pouco significativas. (ORTIGÃO, 2018, p. 11)

Além da atestada ineficácia dessas orientações, tendo em vista os resultados das avaliações, observamos certa descontinuidade nos discursos do Banco Mundial, por exemplo, em suas tentativas de tornar nossas políticas educacionais mais viáveis economicamente. Vejamos dois momentos distintos dessas orientações.

No primeiro momento, 2011, em um documento intitulado Orientações pós-crise, o Banco Mundial propõe um roteiro para uma década de investimentos que recuperem as perdas da última crise econômica internacional. A bolha produzida pela economia americana reverberou em todo o mundo, principalmente no mundo subdesenvolvido ou em desenvolvimento, mesmo que sob o efeito marola.

Em abril de 2011, o Banco Mundial lançou sua Estratégia de Educação de 2020, Aprendizagem para Todos: Investimento no Conhecimento e nas Aptidões das Pessoas para Promover o Desenvolvimento, um roteiro para os próximos 10 anos que enfatiza a necessidade de investir antecipadamente, investir com inteligência e investir para todos. O Banco Mundial enfocará o trabalho em parceria estratégica para ajudar os países em desenvolvimento a fortalecerem seus sistemas educacionais além de insumos e a construir uma base de conhecimento global para reforma. Novas ferramentas para avaliar os sistemas educacionais oferecerão um padrão referencial para as políticas educacionais de acordo com os padrões globais baseados em evidências e melhores práticas, desde o desenvolvimento da primeira infância até o ensino superior. (Banco Mundial, 2011, p.8)

Não obstante, em relatório de 2017, do mesmo Banco Mundial, Um ajuste justo: uma análise da eficiência e equidade do gasto público no Brasil, observamos centenas de orientações para todos os setores das políticas públicas do Brasil, incluindo a Educação, mas por outro paradigma, muito embora a década da proposição anterior (2011) não tenha chegado ao seu fim. Trata-se, segundo consta em seu prefácio, de uma encomenda do próprio governo brasileiro, face a um período de estabilidade econômica e consequente prosperidade de seus "números". A tônica do relatório consiste na máxima gastar menos com maior eficácia. No setor educacional, em particular, os investimentos em conhecimento e aptidões pessoais, propugnados em 2011, cedem lugar a um pensamento que associa diminuição dos gastos, aumento da "produtividade", elogio da iniciativa privada e ameaças de desemprego. Os problemas educacionais brasileiros recaem todos sobre uma suposta ineficiência dos professores 
em múltiplos sentidos.

As crescentes despesas públicas e a queda nos números de matrículas públicas resultam em um maior gasto por estudante e em razões aluno-professor ineficientes. Para municípios mais ricos a eficiência é ainda mais baixa dada a transição demográfica mais acelerada, o que resulta em uma redução mais rápida do número de alunos na rede pública. A obrigatoriedade constitucional de se gastar 25 por cento das receitas tributárias em educação contribui para que tais municípios aumentem os gastos por aluno de forma mais acelerada. Esse gasto adicional nem sempre se traduz em maior aprendizado, o gera ineficiências. Além de uma razão aluno-professor relativamente baixa, o sistema público de educação no Brasil é caracterizado por baixa qualidade dos professores e pelos altos índices de reprovação. Todos esses fatores levam a ineficiências significativas. (Banco Mundial, 2017, p. 122)

As comparações entre o setor público e o privado, na área educacional, deixam claras as intenções do Banco em diminuir o papel do Estado nas políticas públicas de Educação em prol da iniciativa privada, em discurso bastante consoante ao Brasil pós Golpe. Esse deslizamento discursivo, digamos assim, nos leva a uma questão intrigante: o Banco Mundial de fato nos orienta ou corrobora orientações governamentais já definidas? A impressão que se tem é que as propostas do Banco Mundial usam sempre a "mesma língua" da corrente majoritária que se instala no poder: uma fala progressivista para um poder progressivista, e uma fala utilitária para um poder utilitário. Afinal o que "pensa" o Banco Mundial? Por que deseja intervir nas políticas públicas educacionais, independente da corrente liberal que se acerca do poder?

Em janeiro de 2019, o Banco Mundial traz a público o Atlas de Objetivos de Desenvolvimento Sustentável de 2018, onde se encontram os 17 Objetivos de Desenvolvimento Sustentável (ODS), dentre eles a Educação. O Banco Mundial intitula-se "um dos maiores produtores mundiais de dados e pesquisas sobre desenvolvimento" e tais objetivos são uma contribuição do background do Banco para o sucesso da Agenda 2030.

Os 17 Objetivos de Desenvolvimento Sustentável (ODS) representam o plano mais ambicioso do mundo para promover o desenvolvimento sustentável de nosso povo e planeta - e estão totalmente alinhados com as metas gêmeas do Grupo Banco Mundial para acabar com a pobreza extrema e construir prosperidade compartilhada de maneira sustentável. Atingir os ODS até 2030 exigirá mais e melhor financiamento, um foco renovado na implementação para melhorar a vida dos mais difíceis de alcançar e melhorias significativas na coleta e análise de dados. Os processos liderados pelos países do Grupo Banco Mundial nos mostraram que os países têm um forte desejo de cumprir os objetivos da Agenda 2030 e, como resultado, nosso apoio a esse trabalho continua a crescer.

(...) Dada a amplitude e abrangência dos ODS, o Atlas é seletivo, enfatizando questões consideradas importantes por especialistas, cientistas de dados e estatísticos do Banco Mundial. A base para qualquer evidência é a confiança: confiar que os dados foram coletados, gerenciados e analisados com responsabilidade e confiar que eles foram apresentados fielmente.

(...) Este Atlas não seria possível sem os esforços de estatísticos e cientistas de dados que 
trabalham em agências nacionais e internacionais em todo o mundo.

Em última análise, o propósito de gerenciar os dados dessa maneira é produzir resultados mensuráveis - maior resiliência a choques econômicos, ambientais e humanitários; mais empregos e oportunidades; e melhor educação, saúde, nutrição e igualdade de gênero sem deixar ninguém para trás. (Banco Mundial, 2019. Tradução e grifos nossos)

Entretanto, a confiabilidade, por parte dos 189 países membros, acerca da veracidade ou plausibilidade de seus dados deve ser pactuada, assim como deve ser assentido o caráter seletivo desses mesmos dados. Não menos importante nessa retórica é a retroalimentação entre políticas públicas e "fundamento" científico, tema desenvolvido por Lemos (2019), e o apelo à resiliência a choques econômicos, ambientais e humanitários. Trata-se, notadamente, da tessitura de um "discurso convincente" que justifica as avaliações e suas mensurações, mas que também se acerca da defesa das competências e, nessa trama, tendo em vista nosso recorte, interessa-nos as possibilidades acerca do capital humano e suas relações com as tais competências e, por conseguinte, com as habilidades socioemocionais. Há algo de suspeito nessa trama.

Muitas críticas surgem às medidas utilizadas para monitorar desempenhos dos estudantes e para avaliar os sistemas educativos, em especial quando são pouco consideradas as diferenças culturais, sociais e econômicas que afetam os resultados médios de estudantes dos diversos países participantes do Programa. Há críticas também sobre as tentativas de imposição de um modelo único de formação das juventudes, pautado na ideia da existência de um sujeito ideal, situado em um mundo globalizado, em que diferenças são negadas e silenciadas em prol de um mundo melhor. (ORTIGÃO, 2018, p. 11)

\section{Capital Humano e calibragem socioemocional}

Gostaríamos de retomar o tema do capital humano porque acreditamos que ele pode nos oferecer subsídios para pensar o problema da competência, não como uma causa, mas como argumento de um falso silogismo. Foucault (2010, p. 279) nos diz que a importância da teoria do capital humano foi fazer com que a economia se imiscuísse em territórios, até então, não econômicos. Os três fatores que possibilitavam a produção de bens, segundo a economia política clássica, são a terra, o capital e o trabalho; sendo este último um campo ainda inexplorado. Não obstante, Adam Smith começar seu pensamento econômico refletindo sobre o trabalho, sua divisão e especialização e a partir disso construir sua análise econômica, o tema acaba tendo pouca importância, inclusive em Ricardo, até o aparecimento da teoria do capital humano cunhada por Schultz, Becker e Mincer, onde o trabalhador deixa de ser "o objeto de uma oferta e de uma procura na forma de força de trabalho" (p. 284) para ser um sujeito econômico ativo.

A aptidão para trabalhar, a competência, o poder fazer qualquer coisa, nada disso pode ser separado daquele que é competente e que pode fazer alguma coisa. (...) É preciso considerar que a competência, que anda a par com o trabalhador é, de certa maneira, a faceta pela qual o trabalhador é uma máquina, mas uma máquina entendida no sentido positivo, já que é 
uma máquina que vai produzir (*) fluxos de rendimentos. (...) Não é uma concepção da força de trabalho, é uma concepção do capital-competência que recebe, em função de diversas variáveis, um determinado rendimento que é um salário, um rendimento-salário, de forma que é o próprio trabalhador que surge como sendo para si uma espécie de empresa. (...) Uma economia composta de unidades-empresas, uma sociedade composta de unidadesempresas: este é, simultaneamente, o princípio da decifração ligado ao liberalismo e a sua programação para a racionalização de uma sociedade e de uma economia. (...) O homo oeconomicus é um empresário, e um empresário de si mesmo. (Foucault, 2010, p. 285286)

O capital humano, segundo sua teoria, é composto de elementos inatos e de elementos adquiridos. Entretanto, o capital humano só interessa aos economistas porque o homo oeconomicus é capaz de utilizar recursos raros, construindo alternativas para um dado fim, produzindo com isso mais economia em domínios ainda inexplorados. O que nos intriga é que isso já é produzido no presente, e como veremos mais adiante, não é preciso esperar por um futuro incerto e monstruoso, tema desenvolvido por Macedo (2018).

O futuro é necessariamente monstro: a figura do futuro, ou seja, esta que apenas pode ser surpresa, esta para a qual não estamos preparados... é anunciada por espécies de monstros. Um futuro que não fosse monstruoso não seria um futuro; seria um amanhã previsível, calculável e programável. Toda experiência aberta para o futuro é preparada ou se prepara para acolher o monstro que chega. (Jacques Derrida, Passages. Apud in MACEDO, 2018, p. 153)

Toda a retórica da preparação dos estudantes para um futuro incerto e complexo, contida nos documentos da OCDE e na própria BNCC, bebe nessa fonte. Formar capital humano, essa competência-máquina capaz de produzir rendimentos, depende de investimentos educativos, tais investimentos vão muito além da instrução escolar ou da profissionalização, observem-se os 17 objetivos de desenvolvimento sustentável, propugnados pelo Banco Mundial. Trata-se de uma biopolítica a administrar capitais humanos, investindo em habilidades socioemocionais. Como mensurá-las e calibrálas?

A BNCC leva em consideração relatórios da OCDE, que é quem conduz o PISA, cujos resultados produzem dados estatísticos que, acredita-se, podem melhorar os "resultados" dos investimentos feitos em Educação pelos Estados - a isso chamam "qualidade de ensino". A OCDE, além dos dados produzidos pelo PISA, vale-se dos estudos produzidos, a partir desses dados, pela Mackinsey \& Company, no que também é seguida pela BNCC.

Mackinsey conclui, conforme seu relatório de 2015, publicado em 2017, que " $A$ mentalidade dos alunos afeta os resultados escolares quase duas vezes mais do que o contexto socioeconômico", tal conclusão, entretanto, não aponta os contextos em que tais mentalidades se formam:

O papel da mentalidade dos alunos no aproveitamento escolar é um campo de estudo 
incipiente, mas intrigante. Em seu livro de 2006, Mindset: a nova psicologia do sucesso [Objetiva, 2017], Carol Dweck argumentou que indivíduos com “mentalidade de crescimento" - isto é, aqueles que acreditam que seu sucesso se deve ao trabalho duro e ao aprendizado - são mais resilientes e tendem a ser mais motivados para o sucesso do que aqueles com "mentalidade fixa", que acreditam que suas habilidades inatas são estáticas e não podem ser desenvolvidas. Dweck também argumentou que a mentalidade de crescimento pode ser ensinada. Em 2016, a Universidade Stanford empreendeu um estudo em grande escala de todos os alunos do $10^{\circ}$ ano no Chile - o maior estudo realizado até hoje - e descobriu que uma forte mentalidade de crescimento é tão importante quanto a condição socioeconômica em termos de prever o aproveitamento escolar. $\mathrm{O}$ estudo também constatou que alunos de baixa renda com forte mentalidade de crescimento conseguem atingir o mesmo alto nível de realização que alunos de alta renda com mentalidade fixa. (Mackinsey, 2017, p. 25)

Acreditamos que tais mentalidades sejam produtos do ambiente socioeconômico e alterar essas mentalidades requer um trabalho de toda a escola, se isto for possível, mas esse trabalho não pode ser feito sem que antes se responda: alterar para onde? Para o quê? E assumir o ônus da resposta. O relatório da Mackinsey (2017) conclui que o aluno que tem mentalidade motivacional bem calibrada sobe um quartil socioeconômico, conclusão compatível com a teoria do capital humano, mas a pergunta que fica é: como fazer essa calibragem se a proposta já vem acompanhada de seu fracasso?

[...] É preciso que fique claro que a mentalidade, por si só, não é suficiente para superar barreiras econômicas e sociais. Esta pesquisa sugere que, no entanto, ela é um poderoso fator para prever os resultados dos alunos, particularmente daqueles que vivem em circunstâncias mais desafiadoras. (p. 32)

Pelo que temos visto até agora, nessa intrincada relação entre Educação e Economia, o desejo de planejar, de dar certo ordenamento, de planificar um futuro globalizado e próspero, "sem deixar ninguém de fora", nas palavras do Banco Mundial, nos remete às palavras de Bruno Maçães (In: Foucault, 2010, p. XV): "para os neoliberais americanos o mercado fornece um princípio facilmente aplicável ao conjunto da vida social", isto é, "o lar doméstico não é em princípio diferente de qualquer outra unidade de produção como a empresa". Isso implica numa visão de mundo e certa constituição do real. Talvez um breve mergulho nesse "real" nos forneça subsídios para uma análise mais aprofundada de sua constituição.

Toda empresa precisa ter missão, visão e valores. Segundo a teoria do capital humano, o trabalhador é uma auto-empresa, portanto deve reger-se pelos mesmos fatores, entendamos o que isso significa na visão de Rafael Liberato:

\section{Por que Missão, Visão e Valores são definições tão importantes para um negócio de sucesso?}

Missão, Visão e Valores são três fatores fundamentais para a elaboração de um Planejamento Estratégico e, mais do que isso: estas definições são importantes, pois servem como

1 Disponível em https://www.senior.com.br/blog/missao-visao-e-valores-de-uma-empresa-entenda-o-que-e-e-como-devem-ser-definidos/. Acessado em fevereiro de 2019. 
direcionadores para todas as decisões a serem tomadas pelos gestores no dia a dia. Elas servirão como base para definição de comportamentos, e devem deixar muito claro qual o caminho a ser seguido, e onde a empresa pretende chegar.

\section{Missão}

Podemos definir a missão como a razão de ser de uma empresa, o propósito pelo qual trabalham e se esforçam os seus sócios e colaboradores. A missão deve ser a carteira de identidade da organização, deve esclarecer qual o seu negócio, ser concisa e objetiva. E por que é tão importante esta definição? Segundo Philip Kotler, "Você pode não aprender muito ao ler a missão de uma empresa - mas você aprenderá muito ao tentar escrevê-la”. Ou seja, a definição da missão é um grande exercício de aprendizado e autoavaliação.

\section{Visão}

Ter uma visão de futuro é simplesmente querer chegar a algum lugar. Todo gestor de alguma forma tem uma visão de futuro para sua organização, mas nem sempre a formalizam, ou definem uma estratégia para alcançar seus objetivos.

\section{Valores}

Os valores são os princípios que regem as ações e comportamentos de todos os indivíduos que fazem parte de uma empresa, como sócios, acionistas e colaboradores. Para entendermos melhor o que são os valores, precisamos distinguir valores e crenças. Uma crença é algo em que eu acredito como sendo certo, justo ou bom. Um valor, por sua vez, é uma crença segundo a qual eu ajo, ou seja, ela está muito mais ligada ao comportamento do que somente à crença.

Criar a Missão, a Visão e os Valores da empresa define o propósito e a identidade da organização.

Podemos daí deduzir que comportamento, identidade e crença são os pilares constitutivos do real socioeconômico neoliberal ideal e sempre futuro. Nossas políticas públicas têm investido em estudos que não só mensuram como tentam calibrar as habilidades que façam prosperar tais competências - competência para disciplinar o próprio comportamento, tendo em vista os objetivos; competência para definir onde se quer chegar e, por fim, competência para crer a tal ponto no futuro promissor de modo que a simples crença se constitua como valor-ação.

Tudo parece engendrado numa clara razão de ser, não fosse pelo futuro, aquilo que ainda não é, que está por vir e que pode não vir. A vida baseada na construção do futuro é uma vida que não se acerca de seu presente, onde o momento vivido não tem importância, tudo é sacrifício em nome de um futuro. A ideia de uma vida escolar vista como sacrifício para um futuro que pode não vir e que, se vier, nunca será o sonhado, é uma vida pouco condizente não só com o presente, a vida vivível, mas com a própria arquitetura existencial e suas relações com a alteridade.

\section{Políticas públicas para um currículo presente}

Do nosso ponto de vista, as condições socioemocionais dificilmente se transmutarão em habilidades socioemocionais a produzir competências socioeconômicas. As 
condições socioemocionais serão sempre circunstanciais, portanto imprevistas e implanejáveis. Assim sendo, nos preocupa a tentativa de imposição do "tipo ideal" para um mundo globalizado e unívoco, conforme crítica de Ortigão (2018) já citada, não no sentido de temê-la, mas no sentido da percepção de que se trata de um gasto muito dispendioso de recursos financeiros, humanos e tecnológicos para um projeto eminentemente infrutífero. Se produz algo, produz, até então, apenas "infelizes": professores doentes, alunos desajustados, avaliações ineficazes, pesquisas a serviço de "discursos convincentes" para projetos pouco confiáveis.

Díaz-Barriga (2018), em seu artigo intitulado A prova Pisa: idealização, cidadania global, imposição cultural e ausência de impacto pedagógico didático, faz uma análise do PISA em três dimensões: política, técnica e pedagógico-didática. Para o autor, o sistema avaliativo do PISA está longe de ser uma boa possibilidade de melhoria dos sistemas educacionais, e entende que o PISA "constitui fundamentalmente uma estratégia de modelização das aprendizagens, dos estudantes como pessoas".

Parece que a démarche "competências socioemocionais" é uma ação em terreno movediço, uma estratégia discursiva para proposições que podem extrapolar nossa imaginação. Nascimento (2018, p. 20) nos diz que: "Não há instituição sem discurso; ao contrário, os fundamentos institucionais se compõem de elementos discursivos e não discursivos, em outros termos, de letra e silêncio, de textos e gestos figurais, de documento e de monumento, entre outros fatores". A produção de sentido simbólico e existencial é uma produção discursiva que norteia as ações na viva vivida, propugnando representações da própria vida vivida (mundo) como se verdade fosse, produzindo condições socioemocionais.

Como falar em políticas públicas, ou mesmo em currículo, se abandonamos - por inviável e, ao mesmo tempo, perigosa - a crença na possibilidade de planejamento do futuro? Resistindo à resposta fácil de que não é preciso fazê-lo - porque há um chamado da alteridade a que precisamos responder (Macedo, 2018) -, temos buscado operar fora do binômio constituído por intervenção centralizada e avaliação de larga escala. A aposta em redes intersubjetivas como uma espécie de antídoto para os modelos economicistas é a forma como vimos tentando pensar o público das políticas, não como uma massa sem face, mas como sujeitos irredutíveis, em suas singularidades complexas.

Em 2016, o CNPq lançou um edital para a área de humanidades e ciências sociais (CNPq, 2016) com uma demanda clara por intervenção. Descrito como tendo por objetivo produzir "conhecimento de modo a subsidiar a elaboração, implementação e avaliação de políticas educacionais, capazes de contribuir para a elevação da qualidade da educação brasileira" (CNPq, 2016), o edital ecoava as políticas para o homo oeconomicus. Pareceu-nos o momento ideal para explicitar que queremos - e sempre o quisemos - participar "do esforço nacional de melhoria da educação básica" (CNPq, 2016), entendendo-o em outras bases. Ao invés de soluções - sempre fáceis para problemas complexos - o compromisso de seguir intervindo na contingência e 
no desconforto, sempre.

Como se trata de um projeto ainda em fase inicial de realização, o que trazemos aqui é um conjunto de reflexões ainda iniciais que se justificam como exemplo de outras apostas. $\mathrm{O}$ momento em que o projeto se iniciou não poderia ser mais propício e, ao mesmo tempo, mais difícil. Com a BNCC recém-aprovada, os municípios estão enfrentando a necessidade de implementá-la, com sua linguagem econômica, como vimos salientando. É o Estado - também fundações privadas e a igreja - intervindo na ação docente, dizendo aos professores o que "devem" ensinar, assim como fornecendolhes o planejamento das aulas. Somando-se a isso, as condições de trabalho e a carga necessária em sala de aula para garantir a sobrevivência, além da culpabilização pelo "fracasso" da educação pública, não é de se estranhar que o magistério seja a profissão com maior índice de síndrome de Bournot no Brasil (Benevides- Pereira, 2012; Lemos, 2019). As dificuldades não param por aí - os cenários que podemos esboçar são sempre menos complexos do que o mundo em que nos encontramos -, mas só com isso já é possível perceber que há questões socioemocionais envolvendo os próprios professores que não podem ser instrumentalizadas na ideia de competência.

O trabalho colaborativo, com a escola, que propomos como elemento constitutivo das políticas públicas em educação, tem inspirações várias que sequer podem ser elencadas. Não há dúvidas da herança de Paulo Freire, ou dos estudos do cotidiano, assim como das abordagens autobiográficas da reconceptualização americana do campo do currículo na ação colaborativa tal como a pensamos inicialmente. Em todas essas tradições, a experiência do humano, em sua complexidade, é trazida de volta para a empreitada educacional, de onde há cerca de um século vem-se tentando expulsá-la em prol do homo oeconomicus. Em todas elas, a certeza de que a esfera do particular é instransponível, ainda que somente possa (ou porque só pode) se estabelecer na relação com a alteridade. Na sacada de Paulo Freire, ao invés de oferecer aos alunos uma "cultura letrada", dar letramento àquela cultura que ali já está. Trata-se da percepção de que as circunstâncias que envolvem cada indivíduo ou grupos de indivíduos, em dado momento de sua existência, incidem sobre suas condições de possibilidade de aprender.

O projeto junto aos professores e às escolas das redes ${ }^{2}$ foi antecedido por algumas experiências realizadas em turmas de didática e currículo dos cursos de formação inicial de professores da UERJ. Em tais cursos, partimos da necessidade de relacionar possibilidades teóricas com dados concretos, o que nos parece ser a demanda mesma de um campo como o das políticas públicas. Em um primeiro momento, os alunos

2 É importante destacar que, em alguns municípios, temos trabalhado em uma escola específica, sem um horário muito definido, organizando nossas atividades conforme as necessidades e possibilidades de todos nós participantes. Em outros, essa ação está se dando em uma espécie de "momento" de formação, em "cursos" organizados com docentes de diferentes unidades escolares. Essa variedade de formatos foi forçada pela redução de recursos imposta pela agência de fomento, mas tem permitido perceber formas distintas de operar na formulação de políticas públicas localizadas em currículo. 
são levados a estudar uma comunidade do Rio de Janeiro, considerando aspectos econômicos e culturais, dados demográficos, mapas religiosos e geografias locais. Busca-se, com isso, construir um quadro tão complexo e profundo quanto possível, evitando generalizações e tematizando os preconceitos. O segundo momento é dedicado a uma viagem panorâmica sobre teorias, clássicas e contemporâneas, dos campos da didática, do currículo e da teoria social. A ideia é que, a partir do contato com uma literatura acessível e de qualidade, criem-se diferentes propostas de ensino-aprendizagem, vislumbrem-se didáticas possíveis, surjam temas diversos a serem tratados. No próprio movimento de "aprender com a teoria", fica explícito que a ação didática de cada professor está atrelada ao seu "modo de ser" e, portanto, o quanto proposições públicas regulatórias oficias se desconectam do chão da escola. Por fim, os cursos terminam com as turmas sendo levadas a pensar o planejamento da escola fictícia: a organização do espaço escolar e das turmas; a escolha das didáticas a serem utilizadas; a adequação dessas e do currículo instituído pelos documentos regulatórios à clientela local; entre outros aspectos. Não menos importante, os alunos são levados a pensar a conciliação das pessoalidades ali em jogo, as diferenças/ divergências próprias dos ajuntamentos humanos a produzir différance, outro "santuário" do imprevisto a desconstruir futuros.

É este foco na différance que buscamos destacar nas atividades de pesquisa colaborativa (Miller, 2005) que vimos realizando junto a professores das redes. 0 planejamento em situação real, mais do que uma tarefa técnica de implementação da BNCC, se pretende um processo que mobiliza toda uma rede intersubjetiva. Colocar em xeque as ideias preconcebidas e estigmatizadas sobre a comunidade, antepondoas às condições existenciais daquelas populações, cria uma imensa multiplicidade de possibilidades de ação pedagógica. O mesmo se aplica a cada um dos alunos, a cada turma, singularidades que as categorizações por vezes não nos permitem perceber. Nesse sentido, o planejamento para o presente é um momento de abertura para a produção de sentidos, tanto simbólicos como existenciais; talvez seja ali o momento em que o currículo emerja, dando sentidos múltiplos àquilo que chamamos mundo, tanto o do professor quanto o dos alunos. O planejamento do currículo, impregnado de pessoalidade, não é a mera ação pedagógica do professor, mas uma rede imbricada e complexa de ações e de vidas. O outro existe como um exterior constitutivo de nós mesmos, o outro é o fator surpresa de nós mesmos, a imprevisibilidade da existência a botar por terra planejamentos tecnicamente bem urdidos e currículos nacionais. O aluno é o "outro" do professor a produzir incômodos cotidianos, o professor é o "outro" do aluno, sempre deslocando-o de sua "área de conforto", ruindo suas crenças, apresentando outros mundos. Nas palavras jocosas, mas não menos angustiantes de Sartre - o inferno são os outros.

Desde a reconceptualização dos estudos curriculares americanos, na década de 1970, currículo e autobiografia se interceptaram, na ideia de currere como "uma tentativa de revelar as formas que as histórias (coletivas e individuais) e esperanças inundam nossos momentos e de estudá-los contando as estórias de nossa experiência educacional" (Grumet, 1981, p.118). Trazer para o currículo a experiência existencial, 
ampliando a noção de conhecimento - termo que parece difícil de apartar do currículo - como "as relações intricadas entre as concepções, percepções e entendimentos da experiência educacional dos sujeitos, as contextualizações que eles fazem dessa experiências no mundo sociopolítico" (Miller, 2005, p.151). Se as perspectivas feministas e pós-estruturais complicam a noção de sujeito, trazemos da reconceptualização essa crença na irredutibilidade da experiência educacional à mesmidade, essa aposta no sentido, imprevisível, dessa experiência para cada um. Talvez pudéssemos dizer o sentido socioemocional da experiência escolar.

Por experiência escolar estamos entendendo uma rede complexa de interrelações, não entre pessoas - como sujeitos previamente constituídos, assumindo lugares sociais -, mas entre múltiplos fatores que constituem a subjetividade, incluindo o linguístico, o racial, o material, o sociocultural e as preferências sexuais, dentre outros (Hekman, 2014). Planejar para o presente é, ao nosso ver, o próprio produzir incessante dessa experiência, que apenas pode ser narrada, talvez e parcialmente, em retrospecto. O que temos produzido com os docentes na pesquisa é nada mais do que vida vivida ali onde nos encontramos. Como método, apenas o compromisso para com a alteridade que nos põe alerta contra toda e qualquer tentativa - sempre lá - de impedir o fluxo da différance.

Mas já não é isso que os professores e todos nós fazemos, viver a vida como dá? Para que precisamos de uma ação, que se pretende política pública, para fazer exatamente o que já é feito e, pelos diagnósticos oficiais, parece não dar resultado? Com Derrida (2010) aprendemos que o cálculo está sempre à espreita e é capaz de aproximar ideias "incalculáveis e doadoras (...) do mal, ou do pior" (p.55). Por isso, uma ação desconstrutiva segue sempre sendo necessária, para deixar emergir o excesso constantemente reprimido. Como prática representacional, a educação produz e está cheia de sentidos, incontroláveis e excessivos, mas também reprimidos por uma norma que, se produtiva, é também controle. Seguir "construindo relações para além das fronteiras categoriais, históricas e discursivas de construções monolíticas, estáticas ou binárias do eu e o outro" (Miller, 2005, p.110) é, portanto, a tarefa política que julgamos responsável e necessária. Apenas produzir efeitos disruptivos incessantes. Definir competências a serem medidas é apostar no controle que, justamente, dificulta a visibilidade do excesso que habita e dá vida a nossas práticas.

\section{Referências}

Anderson-Levitt, K. (2017). Global Flows of Competence-based Approaches in Primary and Secondary Education. Cahiers de la recherche sur l'éducation et les savoirs, 16 (1): 47-72.

Banco Mundial. (2011). Orientações pós-crise. Disponível em http://siteresources. worldbank.org/EXTANNREP2011/Resources/8070616-1315497380273/P_Chap 
ter1_PostcrisisDirections.pdf. Acessado em fevereiro de 2019.

Banco Mundial. (2017). Um ajuste justo: uma análise da eficiência e equidade do gasto público no Brasil. Disponivel em: https://cdn.oantagonista.net/uploads/2017/11/ Banco-Mundial-Um-Ajuste-Justo.pdf. Acessado em fevereiro de 2019.

Banco Mundial. (2019). Atlas of Sustainable Development Goals From World Development Indicators 2018. Disponivel em : file://C:/Users/GUILHERME/AppData/ Local/Packages/Microsoft.MicrosoftEdge_8wekyb3d8bbwe/TempState/Downlo ads/9781464812507\%20(1).pdf. Acessado em fevereiro de 2019.

Brasil, MEC. (2017). Base Nacional Comum Curricular. Brasília: MEC. Disponível em: http://basenacionalcomum.mec.gov.br/wp-content/uploads/2018/02/bncc-20de z-site.pdf. Acessado em fevereiro de 2019.

Benevides-Pereira, Ana Maria Teresa (2012). Considerações sobre a sindrome de burnout e seu impacto no ensino. Boletim de Psicologia, 2012, Vol. LXII, No 137: 155168. Acessivel em http://pepsic.bvsalud.org/pdf/bolpsi/v62n137/v62n136a05.pdf. Acessado em 15/12/2017.

Carvalho, R. S. de; Silva, R.R.D. da. (2017). Currículos socioemocionais, habilidades do século XXI e o investimento econômico na educação: as novas políticas curriculares em exame. Educar em Revista, 63, 173-190. Disponivel em http://www.scielo.br/ pdf/er/n63/1984-0411-er-63-00173.pdf. Acessado em fevereiro de 2019.

CNPq. (2016). Chamada CNPq n²2/2016 - Pesquisa e Inovação em Ciências Humanas, Sociais e Sociais Aplicadas. Brasília: CNPq, 2016. Disponível em: <resultado. cnpq.br/8345324771782023>. Acesso em: 20 maio 2018.

Derrida, J. (1989). Psyche: inventions of the Other. In Waters, L.; Godzich, W. (eds). Reading de man reading. Minneapolis: University of Minnesota Press.

Derrida, J. (2010). Força da lei. São Paulo: Martins Fontes.

Diáz-Barriga, A. (2018). A prova Pisa: idealização, cidadania global, imposição cultural e ausência de impacto pedagógico didático. In Ortigão, M.I.R. (Org.) Políticas de avaliação, currículo e qualidade: diálogos sobre o Pisa. Curitiba: CRV, p. 19-38)

Foucault, M. (2010). Nascimento da Biopolítica. Lisboa: Edições 70.

Grumet, M. (1981). Restitution and reconstruction of educational experience: an autobiographical method for curriculum theory. In: Lawn, M.; Barton, L. (Orgs.). Rethinking curriculum studies. Londres: Croom Helm.

Hekman, S. (2014). The feminine subject. Cambridge: Polity Press. 
Lemos, G. A. R. (2014). O sujeito descentrado e a educação como estética. Tese de Doutorado. Rio de Janeiro: UERJ/ProdEd.

Lemos, G. A. R. (2019). Currículo e docência: regulação e escape. In Macedo, E.; Menezes, I. (Org.). Currículo, política e cultura: conversas entre Brasil e Portugal. Curitiba: CRV, 41-56.

Lins, L. M. (2013). Economia e Educação: um estudo da relação entre estrutura produtiva e demandas educacionais nas regiões metropolitanos de São Paulo e Belo Horizonte. Dissertação de Mestrado. São Paulo: FFLCH - USP.

Macedo, E. (2018). A teoria do currículo e futuro monstro. In Lopes, A.; Siscar, M. (Org.) Pensando a política com Derrida: responsabilidade, tradução e porvir. São Paulo: Cortez, p. 153-177.

Mackinsey \& Company. (2017). Fatores que influenciam o sucesso escolar na América Latina: Relatório 2015. Disponivel em: https://www.mckinsey.com/ /media/mckin sey/industries/social\%20sector/our\%20insights/what\%20drives\%20student\%20 performance\%20in\%20latin\%20america/fatores-qu-port.ashx. Acessado em janei ro de 2019.

Miller, J. L. (2005). Sounds of silence breaking: women, autobiography, curriculum. New York: Peter Lang.

Nascimento, E. (2018). O debate Foucault e Derrida: políticas da interpretação. In Lopes, A.C.; Siscar, M. (Orgs.). Pensando a política com Derrida: responsabilidade, tradução, porvir. São Paulo: Cortez, p. 13-37.

Ortigão, M.I.R. (Org). (2018). Políticas de avaliação, currículo e qualidade: diálogos sobre o Pisa. Curitiba: CRV.

Rodrigues, C. E. S. de L. (2015). Habilidades socioemocionais: a ocde e seu projeto de governança educacional global. $37^{a}$ Reunião Nacional da ANPEd. Florianópo lis:ANPEd. Disponível em: https://educacaoemocional.com.br/wp-content/uplo ads/2018/07/Anped-Habilidades-socioemocionais-a-OCDE-e-seu-projeto-de-go vernança-educacional-global.pdf. Acessado em fevereiro de 2019.

\section{Biografia}

\section{Guilherme Augusto Rezende Lemos}

É doutor pelo Programa de Pós-Graduação em Educação da UERJ, na área de 
currículo, com a tese "O sujeito descentrado e a educação como estética", sob a orientação da Professora Elizabeth Fernandes de Macedo, com estágio de doutoramento sanduíche na Universidade do Porto - Portugal, bolsa FAPERJ, agosto a dezembro de 2011. Possui mestrado em Filosofia pela Universidade do Estado do Rio de Janeiro (2001). Atualmente é Professor Adjunto da Faculdade de Educação da Universidade do Estado do Rio de Janeiro, atuando principalmente nos seguintes temas: Educação, currículo, didática, formação de professores, cultura e filosofia. Professor do Programa Programa de pós graduação em Educação da UERJ - PROPED.

ORCID: https://orcid.org/0000-0002-0518-6719

\section{Elizabeth Macedo}

Possui graduação em Química pela UERJ, mestrado e doutorado em Educação, respectivamente pela UFRJ e UNICAMP. Tem pós-doutorado pela University of British Columbia. Atuou como Visiting Scholar na University of British Columbia, na Columbia University e na New York University (estágio sênior, CNPq, 2019). Atualmente é professora Titular da Universidade do Estado do Rio de Janeiro. Tem atuação na administração do sistema de ciência e tecnologia, seja na Universidade, seja em agências de fomento. É Cientista do Nosso Estado da FAPERJ, bolsista 1A do CNPq e procientista da FAPERJ/UERJ. Coordena o grupo de pesquisa Currículo, cultura e diferença do CNPq. Suas pesquisas em andamento têm se concentrado em mapear as redes de demandas (ou de poder) em ação durante a elaboração de currículos nacionais, bem como como durante os processos de implementação nos estados.

ORCID: https://orcid.org/0000-0003-4886-8709 